\title{
Aspectos administrativos de la Ley de Caza
}

\author{
$351.823 .1(46)$
}

por

JOSE M.a BOOUERA OLIVER

SUMARIO: I. DELIMITACION DE LOS ASPECTOS ADMINISTRATIVOS DE LA LEY DE CAZA.-II. LAS PRINCIPALES MANIFESTACIONES DEL PODER ADMINISTRATIVO EN LA NUEVA LEY DE CAZA: 1. LiCENCIAS dE CAZA. 2. Las aUtorizaciones de conducción y suelta de piezas. 3. La fiJación de las VEdas. 4. La creación de COTOS. 5. La imposición de SANCIONES POR INFRaCciones administrativas en materia de caza--III. EL ACOTADO DE TERRENOS MUNICIPALES Y EL ARRENDAMIENTO DEL DERECHO A CAZAR EN ELLOS.IV. CONCLUSION.

\section{DELIMITACION DE LOS ASPECTOS ADMINISTRATTVOS DE LA LEY DE CAZA}

Determinar lo que es administrativo en la Ley de Caza de 4 de abril de 1970 y en cualquier realidad legislativa, resulta muy delicada tarea, pues para ${ }^{\circ}$ conseguirlo debemos emplear, como piedra de toque, el concepto de lo jurídico-administrativo y todavía existe una viva discusión sobre cuál sea este concepto.

Sin salirnos del análisis de la regulación de la caza, recordaremos muy brevemente los criterios básicos que se emplean para definir lo jurídico-administrativo.

Royo Villanova (1) dice que «las relaciones que en mate-

(1) Royo Villanova, Elementos de Derecho administrativo, II, Valladolid, Santarén, 1964-65, pág. 588. 
ria de caza se establecen entre particulares son de Derecho privado (civil), y las que con motivo de la caza se entablan entre particulares y el Estado, son de Derecho público (administrativo)». Según este autor, la presencia del Estado, en una relación jurídica referente a la caza, la convierte en relación jurídicoadministrativa. El Derecho que la regule será Derecho administrativo. Emplea, pues, un criterio subjetivo para la conceptuación de lo administrativo.

Clemente de Diego (2) manifiesta que la caza es materia que «se considera como de Derecho administrativo y como de Derecho civil; lo primero, por el aspecto público que envuelve (seguridad y salubridad públicas; conservación y reproducción de los animales); lo segundo, por el aspecto de relación entre particulares que lleva consigo...». Para este autor, el fin de la actividad constituye la nota esencial de lo administrativo. Las normas que en la Ley de Caza regulan la actividad dirigida a conseguir la seguridad, la salubridad pública, la conservación y la reproducción de los animales son normas administrativas. Criterio teleológico, pues, para lo administrativo, aunque para el Derecho civil Clemente de Diego sigue empleando el de los sujetos-relación entre particulares-.

Los dos criterios recordados-subjetivo y teleológico-puros o combinados entre sí, son los que encontramos casi siempre en los cimientos de la mayor parte de las concepciones del Derecho administrativo.

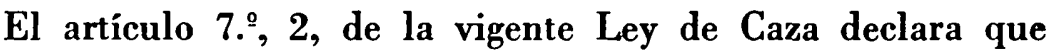
«compete al Ministerio de Agricultura ... promover y realizar cuantas actuaciones sean precisas para alcanzar los fines perseguidos por la presente Ley ("la protección, conservación y fomento de la riqueza cinegética nacional y su ordenado aprovechamiento en armonía con los distintos intereses afectados", según el artículo 1. de la misma Ley), analizar e investigar los diversos factores que condicionan la existencia de la caza y estimular la iniciativa privada en la cría de piezas de caza y en la repoblación de terrenos cinegéticos».

(2) Cuemente de Dieco, Curso elemental de Derecho civil, III, Madrid, 1928, página 241 . 
El artículo 27 del Decreto de 10 de octubre de 1958, llamado de Gobernadores, confiere a éstos, en su respectiva Provincia, competencia para establecer condiciones adecuadas para el ejercicio de la caza, impedir la extinción de las especies no dañinas, vigilar y. fomentar la riqueza cinegética.

Por consiguiente, de conformidad con el criterio subjetivo de lo administrativo, siempre que el Ministerio de Agricultura, el Gobernador civil, o cualquier otro órgano del Estado, lleven. a cabo las actividades enumeradas en los preceptos que acabamos. de citar darán nacimiento a relaciones jurídico-administrativas. Las normas de la Ley de Caza que regulen estas relaciones serán. administrativas.

Cuando el Ministerio de Agricultura venda o done animales. para repoblar terrenos de caza, originará relaciones administrativas; cuando ofrezca un premio a quien mate animales dañinos, también su actividad será administrativa; $y$ así podríamos continuar con otros muchos ejemplos.

La anterior conclusión choca con nuestras categorías jurídicas fundamentales, pues la venta, la donación, la oferta de recompensa son para todos, o para casi todos, negocios jurídicos privados. Negocios jurídicos que, cualquiera quien sea su autor, Estado o personas individuales, se rigen por los mismos principios. Calificarlos de administrativos por el solo hecho de proceder del Estado no parece lógico. El Estado no cambia con su. presencia la naturaleza de las relaciones jurídicas. No es aceptable la afirmación de que la participación de la Administración. pública en una relación jurídica que tiene por objeto a la caza. es administrativa y administrativos los preceptos de la Ley de: Caza que la regulen.

Parecidas consideraciones pueden hacerse con respecto a la. concepción teleológica de lo administrativo, segundo de los criterios recordados. En principio, cualquier fin puede conseguirse con medios privados o con medios públicos. La consecución de un fin calificado legislativamente de público no exige el empleo de un medio público.

El Estado puede adquirir una finca para constituir un aeródromo, bien comprándosela a su propietario o bien expropián- 
dosela. En el primer caso, tenemos un negocio jurídico civil, la compraventa; en el segundo, un acto administrativo del Estado, la expropiación. Ambos consiguen idéntico fin, que el Estado sea el propietario de la finca. No podemos sostener, pues, que todo acto jurídico dirigido a cumplir un fin público es administrativo y que son normas administrativas las que regulan su consecución.

Lo que ocurre es que cuando a la consecución de un fin de interés público se opone un interés privado debe de existir, y existe, un sujeto dotado de un poder capaz de neutralizar o destruir dicho obstáculo. En cambio, cuando a un fin de interés privado se opone otro interés privado, quien persigue el primero no tiene a su disposición un medio jurídico que le permita hacerle prevalecer sobre el otro interés privado.

Al servicio de los fines públicos deberá encontrarse siempre la posibilidad de imponer a los sujetos particulares obligaciones y de otorgarles derechos incluso en contra de su voluntad. Esta posibilidad o potencia se denomina el «poder administrativo». Este poder crea unilateralmente relaciones jurídicas que por su modo de constituirse y eficacia en Derecho reciben el nombre de relaciones jurídico-administrativas.

La compraventa de la finca, en el ejemplo antes expuesto y en todos los posibles ejemplos, es un negocio jurídico privado porque sus consecuencias jurídicas nacen de las voluntades de los dos sujetos que participan en la creación del negocio jurídico; mientras que la expropiación forzosa es administrativa porque sus efectos los crea y los impone una sola voluntad, la del sujeto dotado de poder administrativo, con valor jurídico siempre que sean conformes con el Ordenamiento jurídico.

Poder administrativo es, pues, la posibilidad concedida por el legislador a determinados sujetos para constituir, modificar, extinguir y declarar unilateralmente e imponer consecuencias jurídicas a otros sujetos con fundamento en una presunción iuris tantum de legalidad. El sujeto con poder administrativo suele tener, además, capacidad jurídico-privada. Sólo emplea aquél para hacer prevalecer su voluntad sobre la de otros sujetos. Es entonces cuando actúa administrativamente. 
La noción de poder administrativo será la que nos permita señalar los linderos de nuestro campo de estudio dentro de la Ley de Caza.

La Ley de 4 de abril de 1970 , según se desprende de su lectura, ha concedido a determinados sujetos, principalmente al Estado, poder administrativo para que conserven la riqueza cinegética del país; conservación que la Ley considera, aunque no lo diga expresamente, un fin de interés general o público. Es la conservación de las especies cinegéticas-dice la sentencia de 20 de febrero de 1965 (Ar. 3.330)-la que impone la intervención de la Administración (dicho con otras palabras, de sujetos dotados de poder administrativo) en la caza.

Los sujetos dotados de poder administrativo no siempre tienen que recurrir al ejercicio de este poder para conservar la caza, pero lo emplearán siempre que, permitiéndolo la Ley, consideren necesario hacerlo.

El Estado español se preocupa y ocupa de conservar la riqueza cinegética no porque sea suya, que no lo-es-puesto que los artículos $4 .^{\circ}$ y 22 de la Ley de Caza mantienen el principio, establecido por el artículo 610 del Código civil, de que los animales que se pueden cazar carecen de dueño, son cosas de nadie-, sino porque considera que la existencia de la caza es buena para la generalidad de los ciudadanos (3).

La caza es un bien carente de titular dominical cuya conservación es de interés público, por esto se emplea con frecuencia el poder administrativo para conservar la caza y encauzar el derecho a cazar. Las disposiciones de la Ley de Caza que otorgan y regulan el ejercicio dé dicho poder serán administrativas.

Pero el Estado, las Provincias, los. Municipios son también titulares del derecho a cazar en los predios de su propiedad, como cualquier otro propietario. No son administrativas las normas que regulan el derecho a cazar del Estado, Provincias y $\mathrm{Mu}$ nicipios en los predios de su propiedad, pues este derecho se ejercita, naturalmente, sin el empleo del poder administrativo.

(3) DE Los Mozos, J. L., «Precedentes históricos y aspectos civiles del Derecho de caza», Rivista di Diritto Agrario, núm. 1, 1972, págs. 225 y sigs. 


\section{LAS PRINCIPAĹES MANIFESTACIONES DEL PODER ADMINISTRATIVO EN LA NUEVA LEY DE CAZA}

Creemos que las principales manifestaciones del poder administrativo en relación con la caza son las siguientes:

1.: Las licencias de caza.

2. Las autorizaciones de conducción y suelta de piezas.

3. $\quad$ La fijación de las vedas.

4." La creación de cotos, y

5. La imposición de sanciones por infracciones administrativas en materia de caza.

Existen, desde luego, otros aspectos administrativos en la Ley de Caza de menor significación. Ahora no nos ocuparemos de ellos.

El interesado por los problemas de la caza, quizá piense que un administrativista no debe dejar de tratar un punto anteriormente no enumerado: el acotado de terrenos municipales y el arrendamiento del derecho a cazar en ellos. En puridad, y consecuente con nuestro criterio de lo jurídico-administrativo antes expuesto, debo afirmar que el arrendamiento del derecho a cazar en terrenos municipales es una cuestión jurídico-privada. El derecho a cazar es-dice la sentencia de 2 de febrero de 1966 (Aranzadi 538)-una de las facultades dominicales de los propietarios de fincas rústicas, y el derecho de propiedad, nadie lo duda, es un derecho privado. También será civil el contrato de arrendamiento de esta facultad dominical, aunque el arrendador sea el Estado, la Provincia o el Municipio.

No obstante, respetuosos con la tradición que lleva al Derecho administrativo el estudio de los contratos civiles de las Entidades denominadas públicas, haremos una excepción a las consecuencias del propio concepto de lo jurídico-administrativo y examinaremos dicha cuestión.

\section{Licencias de CAZA.}

Hace ya algunos años, los tratadistas de Derecho administrativo discutieron apasionadamente si los particulares podían exi- 
gir de la Administración la efectividad de derechos subjetivos que aquélla previamente no les había concedido. Con otras palabras, discutían si la ley, en algunos casos, confiere directamente o no a los particulares la facultad de exigir de la Administración una conducta determinada con respecto a ellos.

Duguit (4) y Hauriou (5) coincidieron en afirmar que los derechos subjetivos de los administrados frente a la Administración sólo nacen de decisiones que ésta adopta con respecto a aquéllos atendiendo a sus características individuales. Los derechos de los administrados, y las recíprocas obligaciones de la Administración, sólo nacen de concesiones de la propia Administración o de contratos en los que ésta sea parte.

La Administración también puede, por motivos de interés público, condicionar el ejercicio de derechos privados-nacidos de negocios jurídicos entre los particulares-a decisiones propias, denominadas autorizaciones, permisos o licencias, para comprobar que dicho ejercicio no perjudica a los intereses públicos.

Más recientemente, se abre camino en la doctrina la tesis opuesta a la mantenida por Duguit y Hauriou: Los particulares pueden recibir directamente de la ley derechos subjetivos que se corresponden con obligaciones de la Administración (6).

Solución de una lógica jurídica absoluta, porque la ley es un acto soberano, la ley lo puede todo, $y$, por consiguiente, puede conceder a los particulares derechos frente a la Administración, como puede de igual modo imponerles obligaciones para con ella.

Existen dos grandes categorías de actos administrativos. Los actos administrativos constitutivos de derechos y obligaciones y los actos administrativos declarativos de los mismos. Los primeros confieren, modifican o extinguen derechos a los administrados, e igualmente les imponen, modifican o extinguen obligaciones. Como consecuencia de los actos administrativos constitu-

(4) Droit constitutionnel, II, 3." ed., págs. 418 y sigs.

(5) Précis de Droü administratif, 12." ed., Paris, Sirey, pág. 396.

(6) Bonnard, R., Le contrôle juridictionnel de CAdministration, Paris, Dolagrave, 1934, páge. 51 y sigs.; Dabzaszs, P., sLo problème du droit a concourir», Revue du Droit Public, núm. 6, 1967, pág8. 1133 y sigs. 
tivos, los particulares pueden o deben hacer cosas que antes no podían hacer o no estaban obligados a hacer.

Los segundos, los actos declarativos, reconocen derechos y obligaciones en los particulares que éstos ya tenían en sus respectivos círculos jurídicos. Los actos declarativos pueden recaer sobre derechos que las leyes otorgaron a los particulares; sobre derechos nacidos de negocios jurídicos privados, o sobre derechos subjetivos creados y concedidos a los administrados por actos administrativos constitutivos.

Los actos declarativos, a su vez, pueden limitarse a reconocer la existencia de derechos y obligaciones, o bien añadir a este reconocimiento la autorización para su ejercicio.

Nos hemos permitido recordar los anteriores conceptos y sus consecuencias, porque nuestra Ley de Caza de 16 de mayo de 1902 (artículos $6 .^{\circ}$ y $7 .^{\circ}$ ), después de reconocer a todos el derecho de apropiarse de la caza (las piezas de caza eran res nullius según el Código civil, aunque en las fincas particulares sólo podían ejercitar este derecho sus dueños), exigía licencia de caza para poder cazar, pues «únicamente podrá cazar el que haya obtenido del Gobernador civil de la Provincia licencia de uso de escopeta y licencia de caza» (artículo 28). En esta Ley la licencia de caza era evidentemente un acto administrativo declarativo de un derecho que, además, autorizaba el ejercicio del mismo (7).

En cambio, la vigente Ley de Caza, que no altera, como antes hemos dicho, el principio de que las piezas de caza son cosas sin dueño, en su artículo $3 .^{\circ}, 1$, dice que «el derecho a cazar corresponde a toda persona mayor de catorce años que esté en posesión de la licencia de caza y cumpla los demás requisitos establecidos en la presente Ley». La licencia de caza, según el tenor literal de este precepto, parece una condición de existencia del derecho a cazar y no un simple requisito formal para su ejercicio. El derecho a cazar corresponde, manifiesta la Ley, a los mayores de catorce años que tengan licencia de caza $y$, además, cumplan los otros requisitos que la misma establece. La nueva Ley de Caza

(7) Pellisé Prats, B., «Caza», en Nueva Enciclopedia Jurídica Seix, III, Barcelona, 1951, pág. 948. 
da la impresión de querer convertir a la licencia de caza en un elemento constitutivo del derecho a cazar; en un acto por el que o con el que se concede el derecho a cazar, como ocurre en los países en que la caza pertenece al Estado (Marruecos, por ejemplo) (8). Según la Ley, la licencia de caza debe sumarse a las otras condiciones legales para que nazca el derecho a cazar.

Podrá argumentarse, frente a la interpretación que hemos dado al citado artículo $3 .^{\circ}$ de la Ley, que no es lógico que si en la misma Ley se reconoce que la caza es un bien que carece de dueño $y$, por tanto, todos pueden apropiárselo, se reserve la Administración del Estado la facultad de otorgar un derecho sobre un bien que no es suyo. Podrá decirse, también, que el nombre de licencias lo reciben habitualmente los actos por los cuales la Administración permite el ejercicio de derechos preexistentes en los particulares. Pero podrá demostrarse en contra de la última observación que algunas leyes y disposiciones administrativas dan el nombre de autorizaciones, permisos o licencias a actos administrativos que indiscutiblemente son constitutivos de derechos. A mí me parece que el artículo $3 .^{\circ}$ de la Ley ha creado un equívoco sobre la naturaleza de lo que denomina licencia de caza que puede originar dificultades. Porque entender que la licencia de caza es un acto administrativo de concesión del derecho a cazar o bien un acto de autorización de su ejercicio, no es una cuestión puramente terminológica (que se resolvería: advirtiendo que cuando la Ley habla de licencias de caza debemos entender concesiones de caza) ni baladí, sino que puede tener importantes consecuencias prácticas.

Las licencias propiamente dichas, en cuanto que condicionan el ejercicio de derechos a los particulares que no pueden quedar a merced de la Administración, son actos reglados en su otorgamiento y en su contenido. La Administración tiene que conceder necesariamente las licencias que los titulares de los derechos le pidan si éstos cumplen los requisitos que las dispo-

(8) Vid. Rocs, E., «Regulación administrativa de la caza y de la pesca fluvial en el Estado de Marruecos», Revista de Administración Pública, núm. 42, páginas 457 y sigs. 
siciones vigentes establecen para su concesión y en la forma en que éstas lo hayan previsto.

En cambio, las concesiones son actos discrecionales en su otorgamiento y en buena parte de su contenido. Nadie puede exigir de la Administración que le conceda un derecho cuya creación y otorgamiento depende únicamente de la voluntad de ésta.

Si la licencia de caza termina, pues, por configurarse como un acto administrativo de concesión, un acto constitutivo del derecho a cazar, nadie podrá exigir a la Administración que le conceda una licencia de caza (9).

En cambio, si continuara considerándose a aquélla como un acto de autorización podría exigirse de la Administración, cuando se cumplen las condiciones establecidas por las leyes y reglamentos, el otorgamiento de la licencia.

Otras muchas cuestiones relativas a las licencias podriamos examinar-su carácter personal (artículo 34 de la Ley de Caza); sus clases (artículos 34 y 36 ) ; la posibilidad de establecer pruebas de aptitud para la concesión de la licencia (artículo 34, 6) ; las autoridades que pueden concederlas (artículo 34,4 y 5 ), etcétera-; pero no nos parece que las normas que regulan estos puntos presenten problemas de interpretación. Advertiremos solamente que el párrafo 7. del artículo 34 de la Ley de 4 de abril de 1970 ha creado un medio para la ejecución forzosa de las sanciones económicas en materia de caza (medio que parece va a ponerse de moda), que no tomó en consideración el artículo 104 de la Ley de Procedimiento: «Los peticionarios de licencia de caza que hubieran sido sancionados ejecutoriamente como infractores de la presente Ley no podrán obtener o renovar dicha licencia sin acreditar, previamente, que han cumplido las penas impuestas o abonado el importe de las multas».

Finalmente quisiéramos hacer notar que el Reglamento de la Ley, en su artículo 36,5 , dice que las licencias de caza carecerán de validez y se considerarán nulas de pleno derecho en

(9) Esto estaría en consonancia con la «administrativización» que la nueva Ley bace de la caza. 
los siguientes supuestos: a) Cuando el titular practique el ejercicio de la caza con armas cuyo uso o tenencia requiera estar en posesión de una autorización especial o carezca de ella. b) Cuando el titular practique el ejercicio de la caza con armas sin estar en posesión del contrato de seguro obligatorio que se prevé en el artículo 52 del presente Reglamento. Se trata, pues, de conductas de los administrados y no de actos de la Administración; de dos infracciones de disposiciones legales por los administrados que se quiere que originen la nulidad de pleno derecho de un acto administrativo como es la licencia de caza. ¿Cómo, pues, el Reglamento se atreve a decir que en estos casos la licencia será nula de pleno derecho? Parece que se trata de una deficiencia técnica importante; una manera totalmente equivocada de decir que las licencias caducarán cuando se infrinjan las obligaciones descritas. El precepto reglamentario citado, que se opone en su tenor literal a lo dispuesto en los artículos 47 y 48 de la Ley de Procedimiento administrativo, no puede configurar causas de nulidad de actos administrativos.

\section{Las aUtorizaciones de CONdUCción Y SUElta de PIEZAS.}

Las autorizaciones para la conducción y suelta de piezas de caza, reguladas por el artículo $32 \mathrm{de}$ la Ley, son sin duda autorizaciones administrativas. «Para importar, exportar, trasladar o soltar caza viva-dice el citado artículo-será precisa la previa autorización del Ministerio de Agricultura ... En época de veda no se podrá transportar ni comerciar con piezas de caza muertas, salvo autorización expresa» (10).

Existe el derecho a transportar mercancías y comerciar con ellas, reconocido por las leyes. El citado precepto de la Ley de Caza prohibe de manera general transportar y comerciar con piezas de caza, pero reserva a la Administración la facultad de hacer excepciones a dicha prohibición. Nos encontramos, pues, con la técnica juridica de las autorizaciones en toda su pureza.

(10) Vid. los artículos 29 y 34 del Reglamento de la Ley de Caza y la Resolución de la Dirección General de Montes, Caza y Pesca Fluvial de 21 de abril de 1971 (B. O. E. del 28). 


\section{LA FIJACIÓN DE LAS VEDAS.}

El derecho de cazar se puede ejercitar siempre que no lo prohiba la Administración mediante la declaración de veda. «Queda prohibido-dice el artículo 31, 1, de la Ley-cazar en época de veda». Prohibición de una actividad durante un período de tiempo sin reserva de excepción. También clara manifestación del poder de policía administrativa.

Según el artículo 23 de la Ley de Caza, «el Ministerio de Agricultura ... fijará, a través de la Orden General de Vedas, las limitaciones y épocas hábiles de caza aplicables a las distintas especies en las diversas regiones españolas».

La Orden General de Vedas, en cuanto disposición administrativa de carácter general-con ella se limita temporalmente el derecho a cazar de un grupo indeterminado de sujetos-, debe publicarse en el Boletín Oficial del Estado (artículo 23, 1, b, de la Ley de Caza). Esta inserción es condición de existencia de la veda, pues la publicación de las disposiciones generales es requisito esencial o de validez de las mismas, según el artículo 1. del Código civil y el artículo 132 de la Ley de Procedimiento administrativo. La Orden General de Vedas se reproduce en el Boletín Oficial de cada Provincia sólo a efectos de su difusión.

En virtud del principio de jerarquía de las disposiciones generales, que fija el artículo 23, 2, de la Ley de Régimen jurídico de la Administración del Estado, los Gobernadores civiles sólo podrán, dentro de sus respectivas Provincias, completar lo dispuesto en la Orden General de Vedas, pero de ningún modo cambiar las fechas de las vedas si aquélla no les faculta expresamente para ello.

Las disposiciones que los Gobernadores civiles adopten en relación con la veda deberán publicarse en los Boletines Oficiales de las Provincias para que tengan validez. Tampoco aquéllas existen, por la misma razón antes apuntada, si no se publican.

Las disposiciones sobre vedas no pueden modificarse si no es por otra disposición posterior del mismo rango y debidamente publicada. Esto es obvio. Pero no es raro encontrar publicadas solamente en la prensa diaria disposiciones con las que se quiere cambiar la fecha o las fechas contenidas en disposiciones publi- 
cadas en el Boletin Oficial de la Provincia. Esto no es posible. Dichos cambios no tienen ningún valor jurídico.

Podríamos repetir aplicándola a la Orden General de Vedas toda la teoría general de las disposiciones administrativas. Pero esto no es oportuno hacerlo ahora.

\section{LA CREACIÓN DE COTOS.}

En cuanto al acotado de las fincas, la nueva Ley de Caza significa un giro radical y claro en relación con la legislación. anterior.

La Ley de 16 de mayo de 1902 disponía, en su artículo 9.? que «todo propietario podrá vedar (acotar en terminología actual) legalmente sus fincas». Bajo el imperio de esta Ley, el acotamiento de las fincas para la caza era, evidentemente, una facultad del dueño de las mismas. En una ocasión, que yo sepa, el Gobernador civil de Logroño pretendió que el acotamiento se considerara un acto administrativo (11).

El Ayuntamiento de San Vicente de la Sonsierra constituyó todo el término municipal en coto de caza y su acuerdo fue aprobado por el Gobernador civil. Este entendió que el acotamiento de dicho término tenía su origen en un acto administrativo y requirió al Juez de Haro de inhibición en un asunto del que éste conocía en relación con dicho estado de coto.

El señor Juez de Haro mantuvo la tesis de que «la constitución de un coto de caza no es una facultad emanada de las atribuciones administrativas, sino del derecho de propiedad privada».

Planteada la cuestión de competencia, el Jefe del Estado declaró por Decreto de 1 de febrero de 1968 que no es de carácter administrativo «ni el derecho a cazar en un determinado terreno acotado, que la Ley de Caza de 16 de mayo de 1902 reserva a sus dueños o arrendatarios o las personas autorizadas: por ellos por escrito, ni el acotamiento mismo, en el que sólo requiere el artículo 9. de dicha Ley de Caza "la visibilidad de

(11) Puede verse Martín-Retortillo Baquer, L., Comentario a la cuestión de. competencia resuelta por Decreto $218 / 1968$, de 1 de febrero, en Revista de Administración Pública, núm. 55, págs. 189 y sigs. 
la acotación ..., pero no un acto administrativo de declaración de acotamiento..."》.

Para la Ley vigente, por el contrario, el acotamiento es el efecto jurídico de un acto administrativo. «Se denomina coto de caza-dice su artículo 15,1 -toda superficie continua de terrenos susceptible de aprovechamiento cinegético que haya sido declarada y reconocida como tal, mediante resolución del Instituto Nacional para la Conservación de la Naturalezans (12).

Los particulares y los Ayuntamientos no pueden, pues, acotar sus fincas, sino pedir a dicho Instituto que declare el acotamiento. «La declaración de coto de caza-añade el número 4.: del citado artículo 15-se efectuará a petición de los titulares o patrocinadores interesados».

Los cotos se crean, por consiguiente, mediante actos administrativos singulares adoptados por el ICONA a petición de los interesados. No se trata de un concierto entre el propietario del terreno o el patrocinador del coto y dicho Instituto, sino de un acto unilateral de la Administración, pero que ésta sólo adopta si los interesados así lo solicitan. Un ejemplo de los que ForsTHOFF (13) denomina actos administrativos necesitados de coadyuvante.

La nueva Ley de Caza ha cambiado totalmente el régimen jurídico del acotado de caza, aunque en el artículo 16, 1, nos diga que «los propietarios o titulares a que se refiere el artículo 6." de esta Ley, podrán constituir cotos privados de caza con arreglo a lo establecido en el presente artículo». En realidad, los propietarios sólo pueden pedir que se constituyan los cotos (14).

(12) En virtud del Decreto-ley de 28 de octubre de 1971, artículo 1., 2 , el Instituto Nacional para la Conservación de la Naturaleza (ICONA) ha asumido las funciones del Servicio de Pesca Continental, Caza y Parques Nacionales, al que se refiere la Ley de Caza en el precepto citado en el texto y en otros muchos, y el Patrimonio Forestal del Estado, que han sido suprimidos.

(13) Tratado de Derecho administrativo, Madrid, Instituto de Estudios Políticos, 1958, págs. 294 y sigs.

(14) «... ya no basta el mero acto de voluntad al amparo de la Ley de 1902, donde un señor ponía sus tablillas y se organizaba el coto... el artículo 15, que ha sido aprobado en la tarde del viernes, precisa una previa declaración administrativa...) (Palabras del ponente señor Pardo Canalís en la sesión del 3 de marzo 
El acotamiento, en cuanto acto administrativo, queda sometido, como todos los actos administrativos, al régimen jurídicoadministrativo.

La agregación de fincas enclavadas a los cotos privados, en defecto de acuerdo entre las partes, también se lleva a efecto mediante una decisión administrativa (artículo 16, 4, de la Ley) e igualmente por actos administrativos se establecen las reglas de los cotos privados integrados por asociaciones de titulares de terrenos colindantes (artículo 16, 6, de la Ley de Caza y artículo 18 de su Reglamento).

\section{LA IMPOSICIÓN DE SANCIONES POR INFRACCIONES ADMINISTRATIVAS} EN MATERIA DE CAZA.

La regulación de las infracciones administrativas en materia de caza plantea la cuestión teórica, difícil e interesante, de encontrar, si es que realmente existe, la nota de distinción entre aquéllas y los delitos y faltas de caza.

La vigente Ley de Caza no nos ha procurado ninguna luz sobre esta cuestión, pues se limita a decir (artículo 46) que «constituirá infracción administrativa de caza toda acción u omisión voluntaria que vulnere las prescripciones de esta Ley o del Reglamento que se dicte para su aplicación y no estén comprendidas en los artículos 42 y 43 de la misma». Estos dos artículos se limitan a enumerar los delitos y faltas de caza.

Cualquiera que sea la esencia de la infracción administrativa de caza, lo cierto es que estas infracciones se castigan con la aplicación de los efectos de un acto administrativo (una sanción administrativa) a diferencia de los delitos y de las faltas que se castigan con actos jurisdiccionales o sentencias. Entre las sanciones administrativas y las penas impuestas por los Jueces sí existe una clara y rotunda diferencia. Los efectos de las primeras (efectos procedentes de actos administrativos) descansan en una presunción destructible de conformidad con el Ordenamiento jurídico que puede, lógicamente, ser destruida. Los efectos de

de 1970 de la Comisión de Agricultura que elaboró el Proyecto de Ley de Caza, Diario de las Sesiones de Comïsiones, núm. 7, pág. 20).

Cfr. también De los Mozos, J. L., «Precedentes históricos y aspectos civiles del Derecho de caza», cit., pág. 257. 
las segundas, cuando las sentencias son firmes, descansan sobre una presunción indestructible, iuris et de iure, de veracidad. Del diferente fundamento del acto administrativo y de la sentencia derivan dos regímenes jurídicos distintos para cada uno de ellos. El Derecho regulador de las sanciones es el administrativo. El Derecho de las sentencias que imponen penas es el Derecho procesal penal.

No examinaré la regulación concreta de las sanciones por infracciones administrativas en materia de caza por ser cuestión que en profundidad sólo puede estudiarse en relación con el Derecho penal y en esta perspectiva el lector encontrará guía más segura en otros trabajos recientemente publicados (15).

La tramitación de los expedientes para imponer sanciones se ajustará a lo preceptuado con carácter general en la Ley de Procedimiento administrativo y los resolverá el Ministerio de Agricultura a través del ICONA (artículo 47 de la Ley de Caza). Las infracciones administrativas prescriben a los dos meses (artículo $47, b$, de la Ley de Caza).

\section{EL ACOTADO DE TERRENOS MUNICIPALES Y EL ARRENDAMIENTO DEL DERECHO A CAZAR EN ELLOS}

Los montes de los pueblos, comunales y de propios, son, quizá, los que proporcionan a la mayor parte de los aficionados a la caza la oportunidad de cazar. Alrededor del aprovechamiento de su caza surgen el mayor número de cuestiones litigiosas. Veamos brevemente qué ha significado para estos problemas la nueva Ley de Caza.

En primer lugar, creo que debo recordar que la nueva Ley de Caza (disposición final tercera) ha derogado expresamente el «artículo 198, sobre caza en terrenos comunales y de propios, del texto refundido de 24 de junio de 1955 de la Ley de Régimen local». Este artículo de la Ley de Régimen local contenía

(15) Rodríguez Devesa, J. M.', Derecho penal español, parte especial, Madrid, 1971, págs. 1101 y sigs.; Ruiz Vabillo, E., «Aspectos jurídico-penales de la.caza», Revista General de Derecho, núms. 321, 2223 y 24, 19:1; Martínez Pereda, J. M., Sanciones y responsabilidades en materia de caza, Madrid, Tecnos, 1972. 
las dos declaraciones siguientes: Primera: La constitución ex lege de los bienes comunales y de propios, cuya caza se adjudique o haya sido adjudicada mediante subasta o concurso, en cotos de caza, «sin necesidad de tener tablillas, hitos o mojones» (párrafo 2. del citado artículo). Segunda: El aprovechamiento de la caza en dichos terrenos podía ser objeto de contratación con arreglo a las normas sobre contratación de la Administración local contenidas en la Ley de Régimen local (Título II del Libro III) o en la legislación especial para casos concretos (párrafis 1. del citado artículo).

En relación con la primera declaración, la derogación del artículo 198 de la Ley de Régimen local tiene por consecuencia que el acotado en favor de terrenos municipales deberá hacerlo el ICONA. En los mismos, además, habrá que poner tablillas, hitos o mojones (vid. supra II, 4) (16).

En relación con la segunda declaración habremos de averiguar si ahora los Municipios pueden o deben contratar el aprovechamiento de la caza en sus terrenos y, en su caso, qué normas regularán esta contratación.

Nos parece que los terrenos municipales con caza pueden constituirse en cotos privados de caza y en cotos locales de caza.

El artículo 16 de la Ley de Caza dispone que «los propietarios o titulares de otros derechos reales o personales (sobre las fincas), podrán constituir cotos privados de caza con arreglo a lo establecido en el presente artículo».

Los Municipios son los propietarios de sus bienes de propios y los titulares de sus bienes comunales cuyo aprovechamiento corresponde a la comunidad de vecinos (17). Esta propiedad

(16) CoRtÉs NúÑEz, J. ( «El procedimiento administrativo en los daños de caza», Revista de Administración Pública, núm. 37, 1962, pág. 312), calificaba de «desdichado» al artículo 198 de la Ley de Régimen local porque facilitaba el «que el titular del derecho a cazar en una determinada extensión de terreno ni caza ni deja cazar, y además abandona lo relativo a la extinción de alimañas». La crítica, pues, parece iba dirigida al párrafo $2 .^{\circ}$ de dicho artículo. También había muchos cazadores que se mostraban partidarios de que los terrenos municipales no se constituyeran en cotos de caza. Esto era una visión muy parcial del acotamiento de terrenos.

(1i) Sobre la afirmación del texto puede verse NiETo, A., Bienes comuna. les, Madrid, Ed. Revista de Derecho Privado, 1964, págs. 263 y sigs. 
y titularidad real les permite con dicha clase de terrenos-al amparo del artículo 16 de la Ley de Caza que acabamos de citar-constituir cotos privados de caza. Confirma esta conclusión, el artículo 21,2 , de la misma Ley al decir que «el aprovechamiento de la caza existente en los montes catalogados constituidos en cotos privados, pertenecientes a Entidades públicas locales, deberá efectuarse de acuerdo con lo dispuesto al efecto en las Leyes de Montes y de Régimen local». Los montes catalogados son de utilidad pública $\mathrm{y}$, sin embargo, pueden quedar constituidosien cotos privados. Por consiguiente, con la misma o mayor razón podrán constituirse cotos privados de caza con bienes de propios.

En cuanto a los comunales, el anteproyecto de la Ley de Caza (artículo 32) prohibía arrendar la caza, y sólo podrían tener la consideración de acotados en el caso de que los vecinos se establecieran en sociedad. Pero la Ley no acogió este criterio y habla solamente-sin distinguir-de terrenos de los $\mathrm{Mu}$ nicipios. Puede, pues, concluirse que también pueden constituirse cotos privados de caza en los terrenos comunales.

Si los terrenos de los Municipios constituyen un coto privado de caza puede ocurrir: 1. ${ }^{\circ}$ Que se trate de montes catalogados y, según el citado artículo 21, 2, de la Ley de Caza, el aprovechamiento podrá arrendarse de conformidad con la Ley de Montes y la Ley de Régimen local. Es decir, podrán y deberán hacer lo mismo que disponía el artículo 198, párrafo 1.ํ, de la Ley de Régimen local para los bienes comunales o de propios de los Ayuntamientos de utilidad pública o de libre disposición, que hemos visto fue derogado expresamente por la vigente Ley de Caza, pues esta Ley conserva la misma regulación para los cotos privados sobre montes catalogados.

2. Que los montes no estén catalogados o se trate de otra clase de terrenos municipales, de propios o comunales, lo que será raro. Entonces será de aplicación el artículo 16, 5, de la Ley de Caza: «El ejercicio del derecho a cazar corresponderá al propietario y a las personas que autorice». El Municipio propietario, como persona jurídica, no puede cazar por sí mismo, 
y tampoco disponer gratuitamente de sus bienes y derechos (18), y a esto equivaldría el que autorizara a cazar sin contraprestación a quien estimara pertinente. Por tanto, la autorización para cazar en favor de terceros o, mejor, el otorgamiento del derecho a cazar, deberá llevarse a cabo mediante el empleo de los procedimientos que la Ley de Régimen local señala para disponer de bienes y derechos municipales. Con lo que de nuevo estamos en que los Ayuntamientos deberán cumplir lo que disponía el artículo 198, número 1, de la Ley de Régimen local, que sólo era una norma de remisión. Es decir, que los Ayuntamientos no sólo pueden sino que deben adjudicar a otras personas sus derechos a cazar en terrenos municipales mediante la adjudicación de contratos en la forma que establece la Ley de Régimen local.

En cuanto a los cotos locales de caza, debemos decir, en primer lugar, que no son, pese al nombre, cotos de las Entidades locales (19), sino cotos que representan conjuntamente al 75 por 100 de los titulares del derecho a cazar de un término municipal y que voluntariamente acceden a otorgar su representación a los Ayuntamientos si éstos patrocinan la creación del coto (también pueden patrocinar la creación del coto local las Entidades locales menores y las Hermandades Sindicales de Labradores y Ganaderos) y al que los Municipios pueden aportar sus propios terrenos, tanto de propios como comunales, e incluso los montes catalogados como de utilidad pública, cuando lo autorice el Ministerio de Agricultura (artículo 17, 1, de la Ley de Caza y artículo 19 de su Reglamento).

Lo que no sabemos es si a las Entidades locales les conviene incluir sus bienes en cotos locales de caza. En estos cotos el Ministerio de Agricultura fija las condiciones técnicas aplicables al aprovechamiento (artículo 17, 5, de la Ley de Caza); se reserva el derecho de tanteo en las adjudicaciones (artículo 17, 5, de la Ley de Caza); la duración de los contratos de arrendamiento del aprovechamiento no puede ser menor de seis años, si se trata de

(18) Vid. artículos 189,2, 196 y 659 de la Ley de Régimen local y articulos 75 y 95 del Reglamento de Bienes de las Corporaciones locales.

(19) El Proyecto del Gobierno los denominaba municipales. Quizá para mayor claridad en la cuestión debió buscarse un término que no fuera municipal ni local. 
caza menor, ni de nueve si fuere de caza mayor (artículo 17, 7, de la Ley de Caza); del importe total de la renta se detraerá el 10 por 100 para el ICONA (artículo 17, 8, de la misma Ley) $y$, aunque no siempre, un 10 por 100 para la Hermandad Sindical Local de Labradores y Ganaderos, por lo que aun cuando se convenga un 10 por 100 para el Ayuntamiento, le será muy difícil compensar las otras cargas.

En cualquièr caso, constituido el coto local de caza, la adjudicación y contratación del aprovechamiento cinegético de los terrenos integrantes del mismo se efectuará por el Ayuutamiento de acuerdo con lo dispuesto en la Ley de Régimen local (artículo 17, 5, de la Ley de Caza y artículo 19, 9, de su Reglamento). Con lo que de nuevo tenemos que los bienes municipales que en dichos cotos se integran quedan sometidos al régimen general de los bienes municipales y los aprovechamientos de estos bienes, como la disposición de todos los derechos patrimoniales de los mismos, deberá hacerse mediante los procedimientos de adjudicación que establece la Ley de Régimen local (20).

Por esto creemos que con la nueva Ley de Caza el régimen del aprovechamiento de los terrenos de caza de los Municipios, pese a la expresa derogación del párrafo $10^{\circ}$ del artículo 198 de la Ley de Régimen local, no ha cambiado de manera fundamental.

\section{CONCLUSION}

La breve exposición que acabamos de hacer de los aspectos administrativos fundamentales de la nueva Ley de Caza en relación con los principios básicos de la Ley de 1902 permiten concluir que la Ley de 4 de abril de 1970 significa una mayor «administrativización» de la caza y también la centralización e incluso concentración de competencias con respecto a la situación anterior.

La primera tendencia general en toda nuestra vida, se aprecia con claridad en la historia de la caza. «El ideal cinegético

(20) «Si fueran varios los Municipios af ectados, la subasta se efectuará en aquel cuya aportación de terrenos sea mayor» (art. 17, 5, de la Ley de Caza). 
—dice Miguel Delibes (21) — es incontestablemente el ejercicio de la caza-en libertad: el hombre libre, sobre tierra libre, contra pieza libre. Y así fue como la caza se ejercitó en los primeros tiempos de la Historia ... Mas las circunstancias fueron cambiando. Los hombres se extendieron, progresaron, dominaron la tierra. Al arco sucedió el fusil y a la Naturaleza abrupta y hosca sucedió el campo productivo, la tierra domesticada. Al propio tiempo que el hombre se multiplicaba, la caza disminuía y antè tal contingencia, fueron surgiendo las trabas y cortapisas... El hombre perdía su libertad, es decir, debía someter su impulso cinegético a un control personal y a un límite de tiempo. La Naturaleza dejaba, asimismo, de ser libre desde el momento en que su acoso se sujetaba a un límite de tiempo y lugar y su multiplicación se activaba artificialmente. En una palabra, surgió la Ley con sus papeles para evitar que en este duelo hombreanimal, tan viejo como el mundo, este último terminara por extinguirse, y con ello, el hombre cazador pasara a ser un recuerdo histórico». Y la Ley se «administrativiza» progresivamente porque tiene que prever cada día mayor participación de los titulares de poder administrativo en la conservación de la caza. Pero una mayor intervención administrativa en el ejercicio de la caza no requiere que aquélla corresponda a la Administración del Estado, ni siquiera que sea lo más conveniente.

(21) La caza de la perdiz roja, Barcelona, Ed. Lumen, 1963. 
REVL-1973, núm. 177. BOQUERA OLIVER, JOSE MARIA. ASPECTOS ADMINISTRATIVOS DE LA ... REVL-1973, núm. 177. BOQUERA OLIVER, JOSE MARIA. ASPECTOS ADMINISTRATIVOS DE LA ... 